\title{
O BRINCAR LIVRE EM COMPOSIÇÕES CURRICULARES NO ENSINO FUNDAMENTAL: PERSPECTIVANDO UMA EDUCAÇÃO MENOR
}

\author{
Daniele Farias Freire Raic ${ }^{*}$ \\ Marilete Calegari Cardoso* \\ Josemary da Guarda de Soura***
}

\begin{abstract}
RESUMO: Este artigo busca tensionar e discutir a ideia do brincar livre como um conteúdo escolar que vem sendo desprezado e invisibilizado pelas proposições curriculares dominantes, seja no ambiente escolar, seja no ambiente domiciliar. Investe no verbo criançar como uma condição da infância com todas as suas astúcias, curiosidades, liberdades e potências de criação. Trata-se de uma cartografia que busca traçar o plano comum, assumindo a transversalidade que lhe é necessária. Desse modo, vai ao encontro de dois outros estudos anteriormente produzidos - Baú Brincante e Catadores do Brincar - cujos acervos permitiram, em seus atravessamentos, capturar registros e narrativas de professores participantes que ajudaram a argumentar e a propor composições curriculares "menores", caras a este estudo atual. Apoiando-se na filosofia da diferença, sobretudo na ideia do "currículo menor", esse trabalho sinaliza para os necessários movimentos de perspectivar currículos abertos ao criançar, como modo de afirmar o desejo da criança e os seus processos de singularização.
\end{abstract}

PALAVRAS-CHAVE: Brincar-livre. “Criançar”. Aprendizagem inventiva. Currículo menor.

\section{FREE PLAY IN CURRICULUM COMPOSITIONS IN FUNDAMENTAL EDUCATION: PERSPECTIVING A SMALLER EDUCATION}

\begin{abstract}
This article seeks to tension and discuss the idea of free play as a school content that has been neglected and made invisible by the dominant curricular propositions, whether in the school environment or in the home environment. It invests in the verb "to child" as a condition of childhood with all its astuteness, curiosities, freedoms and powers of creation. It is a cartography that seeks to outline the common plan, assuming its necessary transversality. In this way, it meets two other studies previously produced - Baú Brincante and Catadores do Brincar - whose collections allowed, in their crossings, to capture records and narratives of the participating teachers who helped to argue and propose "smaller curriculum" compositions, dear to this current study. Based on the philosophy of difference, above all on the idea of the "smaller curriculum", this work signals the necessary movements to envisage open curriculum for "to child", as a way of affirming the child's desire and its processes of singularization.
\end{abstract}

KEYWORDS: Free play. "to child”. Inventive learning. Smaller curriculum.

\footnotetext{
* Doutora em Educação pela Universidade Federal da Bahia (UFBA); Professora da Universidade Estadual do Sudoeste da Bahia (UESB); Professora do Programa de Pós-Graduação em Educação (PPGEd/UESB) e do Programa de Educação Científica e Formação de Professores (PPG.ECFP/UESB). E-mail: daniele.freire@uesb.edu.br. Orcid (https://orcid.org/0000-0002-1137-736X).

** Doutora em Educação (UFBA). Professora Adjunta do Departamento de Ciências Humanas e letras - DCHL/ UESB.

Doutora em Educação - Universidade Federal da Bahia. Professora do Programa de Pós-Graduação em Educação (PPGEd/UESB). Pesquisadora do Grupo de Pesquisa em Educação, Didática e Ludicidade - GEPEL/UFBA. E-mail:marilete.cardoso@uesb.edu.br Orcid: https://orcid.org/0000-0002-4088-8249.

*** Mestranda do Programa de Pós-Graduação em Educação (PPGEd) da Universidade Estadual do Sudoeste da Bahia (UESB); Assistente em Administração da Universidade Federal do Recôncavo da Bahia (UFRB).

E-mail: josemarry2@gmail.com. Orcid (https://orcid.org/0000-0003-3818-5912)
} 
"Dia após dia nega-se às crianças o direito de ser crianças. Os fatos, que zombam desse direito, ostentam seus ensinamentos na vida cotidiana. [...] Muita magia e muita sorte têm as crianças que conseguem ser crianças".

(GALEANO, 2011, p.11)

\section{Introdução}

As questões curriculares atravessam nossos estudos há algum tempo, desafiando-nos aos contínuos movimentos de problematizações e tensionamentos a fim de pespectivarmos currículos que favoreçam a construção de aprendizagens que aproximem as crianças de suas potências de agir. $\mathrm{Na}$ contramão de nossas intenções, vemos insistentes práticas curriculares confortavelmente assentadas em modelos pedagógicos que induzem ao assujeitamento e ao ajustamento da pessoa aos sistemas capitalísticos $^{1}$, os quais requerem a produção de subjetividades modelares. Em que pese nossas possibilidades, temos tensionado tais práticas no sentido de aglutinarmos forças moleculares e intensas capazes de afirmarem o desejo das crianças e aproximá-las do que podem seus corpos, como nos diz Spinoza (2020). Assim, investimos nesse texto a ideia da criança-cartógrafa, a qual explora seus meios, produz seus mapas, lança-se ao mundo e com ele se com-funde.

Se um dia a humanidade compreendeu a criança como um adulto em miniatura, como acontecia na época medieval, hoje a temos em sua natureza pululante, vibrátil, destemida, cartógrafa de seus mundos. Todavia, mesmo que os discursos assim falem dela nos tempos hodiernos, não podemos perder de vista a captura de seus desejos pelos processos de subjetivação nos quais estão submetidas, facilmente notados em enunciados do tipo: "o que você quer ser quando crescer?", "você é igualzinho a seu pai”, "isso não é coisa de criança" ou mesmo ao referir-se aos adultos, afirmações do tipo "você está agindo como uma criança". Esses recursos da linguagem, que significam modos de ser criança (e também de ser adulto) têm nas instituições, tais como as famílias, as igrejas, as escolas dentre outras, suas importantes aliadas. Dentre essas instituições, destacamos a escola. Então, no intuito de pensarmos por dentrofora dela, nos colocamos em modos de provocações frente aos seus currículos. Nessa direção, como um exercício inicial de quem quer ir produzindo pistas para produzir e territorializar nosso objeto-problema, perguntamos: como os currículos têm operado no sentido de produzir subjetividades assujeitadas e ajustadas ao sistema capitalístico? Quais os sentidos e significações são atribuídos às crianças escolarizadas? De que maneira as práticas escolares capturam o desejo das crianças e as afasta de suas potências de agir? Nas práticas curriculares, qual o espaço para criançar? As questões aqui postas, ainda em modos de problematizações, foram nos ajudando a compor esse trabalho que ora apresentamos.

\footnotetext{
${ }^{1}$ Utilizamo-nos da expressão de Guattari (GUATTARI; ROLNIK, 2010) a fim de afirmar que mais que a relação de valores econômicos, o sistema capitalista precisa investir na produção de subjetividades alinhadas aos seus princípios, como uma espécie de "matéria prima" para o desenvolvimento do capital mundial integrado (CMI).

2 Propomos e assumimos o verbo criançar como uma condição da infância com todas as suas astúcias, peraltices, curiosidades, atitudes destemidas, arrojos, criação etc.
} 
Os desafios nos quais nos colocamos ao perspectivarmos aberturas curriculares para "o que pode um corpo" em suas potências foram avolumados a partir do ano de 2020, quando fomos surpreendidos de maneira abrupta pela pandemia causada pelo novo coronavírus, denominado SARSCoV-2 e, consequentemente, pelas estratégias de enfrentamento adotadas pelos chefes de Estados frente à crise que se estabeleceu na área da saúde, cujos desdobramentos recaíram em todas as dimensões públicas, incluindo a educação.

Com as medidas sanitárias adotadas, passamos a conviver com o distanciamento social e o trabalho remoto para algumas atividades; outras, tidas como não essenciais, foram suspensas à espera de "melhores dias", como foi o caso da educação escolar. No entanto, com o avanço da pandemia, assistimos a um crasso agravamento das desigualdades sociais e econômicas na garantia do direito à educação que se manifesta, sobretudo, na incapacidade do Estado em propor e manter políticas de inclusão digital para a população usuária dos serviços da escola pública, em que destacamos o estado da Bahia e o município de Jequié-BA, onde temos desenvolvido nossos estudos há alguns anos.

Após um $\mathrm{ano}^{3} \mathrm{em}$ que as atividades escolares presenciais foram suspensas e que, em muitos sistemas públicos de ensino brasileiros sequer foram iniciados os trabalhos pedagógicos remotos e, em outros, a exemplo da rede estadual da Bahia ${ }^{4}$, que somente retomaram as atividades escolares de maneira remota em 15 de março de 2021, nos movimentamos em modos de resistência e de militância em defesa da educação como uma atividade essencial, reafirmando o necessário compromisso do poder público em criar as condições do acesso e da permanência das crianças e jovens na escola. Decorre daí outra questão que se junta as já colocadas anteriormente: o que as escolas estão propondo como atividades curriculares para as crianças considerando a ambiência domiciliar?

Em nossas observações cotidianas pudemos perceber que as discussões em torno das atividades curriculares vêm se dando em torno de "recuperar" um conteúdo escolar "perdido" em função da suspensão das aulas. Vemos que há uma preocupação em levar aos domićlios das crianças uma agenda de atividades pedagógicas recorrentemente alinhadas com modelos cognitivistas, deixando em suspensão as práticas pedagógicas que acessem ao lúdico nas proposições pedagógicas. Das diversas falas de mães e pais e outros cuidadores, retiramos um comum incômodo sobre os desafios que recobriram seus ombros ao assumir a orientação escolar de seus filhos; as crianças, por sua vez, vêm demonstrando sustentados desinteresses com as atividades escolares tidas por muitas propostas pedagógicas como as essenciais para seu desenvolvimento.

É do lugar de nossas compreensões e de problematizações que desejamos com esse texto tensionar e discutir o fato de que há um conteúdo escolar que vem sendo desprezado e invisibilizado

\footnotetext{
3 A Covid 19 foi considerada pandemia pela Organização Pan-Ameicana de Saúde (OPAS) em de 11 de março de 2020. https: $/ /$ www.paho.org $/$ bra/index.php?option $=$ com content\&view $=$ article\&id=6120:oms-afirma-que-covid-19-e-agoracaracterizada-como-pandemia\&Itemid $=812$

${ }^{4}$ Esse retorno não está acontecendo simultaneamente nos 417 municípios baianos, uma vez que que cada ente federado tem competência para organizar seu calendário escolar.
} 
pelas proposições curriculares, seja no ambiente escolar, seja no ambiente domiciliar: o brincar livre das crianças. As nossas experiências e nossos estudos vêm nos deixando ver que a brincadeira é um tipo de "premiação", utilizada tanto pelos professores quanto como pelos familiares, como recompensa depois que as obrigações tenham sido cumpridas pelas crianças. Para nós, o brincar livre como recompensa fere o sentido da brincadeira como um dispositivo formativo indispensável para afirmar e aproximar as crianças de seu criançar.

As proposições curriculares comumente não reivindicam o espaço do brincar livre como atividade curricular potente e necessária ao desenvolvimento das crianças. Então, partindo de nosso objetivo e de nossa pista inicial, voltamos nossas atenções para as proposições curriculares para a etapa dos anos iniciais do ensino fundamental. Por quê? Mais uma vez seguimos a pista de nossas problematizações iniciais para afirmar que tem sido cada vez mais restrito e reduzido o tempo "de brincar" para as crianças de seis a dez anos. Na maioria das práticas das quais nos aproximamos, a brincadeira livre é mais recorrente na educação infantil, ainda assim, há uma forte tendência em pretender direcioná-la, perdendo o sentido que aqui colocamos.

Para a realização desse trabalho nos apoiamos no método cartográfico e seguimos em busca de traçar um plano comum que, segundo Kastrup e Passos (2016, p. 17), “[...] não pode, de modo algum, ser entendido como homogeneidade ou abrandamento das diferenças entre os participantes da investigação (participantes e coisas)". Para os autores, o comum é “[...] produzido pela transversalização realizada por práticas de participação, inclusão e tradução” (idem, p. 20). Nessa direção esses pesquisadores nos ajudam a ver que há o paradoxo da inseparabilidade das ideias de comum e de heterogeneidade. "E por que traçar um plano comum na pesquisa cartográfica?", perguntaríamos um cartógrafo apressado. Sobre isso, concordando com Kastrup e Passos, utilizamo-nos de seus argumentos para dizer:

É comum o que, na experiência, é vivido como pertencimento de qualquer um ao coletivo. Trata-se de um conceito político por excelência, já que comum é a experiência de 'decisão concertada' a que somos convocados e mesmo forçados a fazer na partilha do coletivo. Entre o lógico (universal) e o político (comum) define-se, portanto, uma diferença de direção na experiência - a montante e a jusante dela - o que nos permite pensar uma coexistência que não abole a fricção e na qual o esforço de construção marca presença (KASTRUP; PASSOS, 2016, p .21).

Quando nos envolvemos com as questões curriculares, sabemos que lidamos com o lógico e o político. Sabemos, também, que lidamos com o dentrofora da escola. Partilhamos e pertencemos e, nesse duplo sentido, nos engajamos na direção de novas feituras. Por isso, esse texto lida com esse universal e esse comum, entremeados, admitindo o plano comum como a transversalização como procedimento.

Para a realização desse artigo, apoiamos em estudos anteriores intitulados Baú Brincante (D’ÁVILA; CARDOSO; XAVIER, 2018), quando foi realizada a observação e os registros

\footnotetext{
5 Trata-se de uma Pesquisa interinstitucional realizada, entre 2016-2018, pelo Grupo de Pesquisa em Educação, Didática e
} 
fotográficos das crianças brincando com materiais não estruturados ${ }^{6}$; essas crianças são estudantes dos três primeiros anos do ensino fundamental, com idade até 9 anos, de numa determinada escola pública, em Jequié- BA. A partir e com esses registros fotográficos foram realizados os ateliês na pesquisa Catadores do Brincar (CARDOSO, 2018) quando os professores puderam trazer seus sentimentos e sensações ao observar essas crianças brincando livremente. Daí, em nosso exercício cartográfico, na busca do universal (que não é homogêneo) e do político (que se afirma no plural), nos lateralizamos com esses estudos e, com eles, assumido toda a heterogeneidade que é própria a um estudo cartográfico, buscamos transversalizar os três estudos (Baú Brincante, Catadores do Brincar e este, que ora apresentamos). Nesse movimento, capturamos o acervo disponibilizado pelas pesquisadoras para nos ajudar a argumentar e a perspectivar composições curriculares "menores".

\section{Criançar... em defesa do brincar livre}

Como já dissemos na introdução desse texto, propomos lidar com o verbo criançar. Essa nossa vontade se constitui como um recurso político de resistência à subjetividade da criança cujas práticas discursivas tendem a significá-la como copista (dos pais, dos heróis...), sem vontade própria, consumista, ingênua, inganhável, manipulável etc. Essas significações são capturas do desejo das crianças que as afastam de suas singularidades. Não vemos as crianças como sujeitos de atributos, do tipo "é". Escapamos dos recursos da filosofia clássica em seus essencialismos, seja formal do idealismo, ou seja, substancial do nominalismo; não defendemos nem um ideal nem tampouco um tipo X ou Y de criança. Queremos, por resistir aos essencialismos, pensar no criançar como acontecimento, singular e singularizante, das crianças em suas multiplicidades. Nesse criançar, a questão do brincar livre se torna tema caro aos nossos estudos.

Frequentemente vemos nas falas de profissionais da saúde, de docentes e de pesquisadores, a necessidade de as escolas pensarem em caminhos que se opõem às pedagogias prescritivas; pensar numa maior potência de possibilidades, em que as crianças possam estar “no seu tempo aión ${ }^{7}$, ou seja, um tempo que é a própria infância” (ABRAMOWICZ, 2019, p.24). Uma educação para que elas possam construir vínculos e experiências, como processo de autoria social. Desse modo, muitas vozes ${ }^{8}$ ecoam: "após-

\footnotetext{
Ludicidade - GEPEL, da Universidade Federal da Bahia - UFBA, sob a coordenação da Professora Dr ${ }^{a}$ Cristina Maria D’Ávila Teixeira, em cooperação entre Programa de Pós-graduação em Educação - PPGE/UFBA e a Universidade Paris XIII, Sorbonne, envolvendo a Universidade do Estado da Bahia - UNEB, sob a coordenação da Professora Dra Antonete Araujo Silva Xavier e a Universidade do Sudoeste da Bahia - UESB, sob a coordenação da Professora Dra Marilete Calegari Cardoso. ${ }^{6}$ Entendemos aqui neste estudo, por materiais não estruturados, como sucatas; isto é, são objetos ou materiais já usados e que são considerados inúteis, porém podem ser reaproveitáveis e utilizados sob novas formas.

${ }^{7}$ Aion é o tempo indeterminado o tempo sem duração. Um fragmento de Heráclito (DK 22 B 52) conecta esta palavra temporal ao poder e à infância, quando ele diz que "aión é uma criança que brinca - (literalmente, "criançando")" (KOHAN, 2004; ABRAMOWICZ, 2019).

${ }^{8}$ Fazemos referência das falas de professoras que participaram do Projeto de Extensão "CiberAteliê Brincante: pesquisa formação sobre o brincar livre nos espaços escolares, em parceria (UESB/UFBA/UNEB), realizado em outubro a dezembro de 2020 (CARDOSO, PEREIRA, XAVIER, 2020; PEREIRA, et al, 2021).
} 
pandemia: brincar é urgente!”, como é descrito por Pereira, et al (2021, p. 19). Nós, de nosso lugar de estudos e de produção, desde já problematizamos que o brincar livre deve ser preservado e estimulado em quaisquer ambientes de aprendizagens.

Por que é tão importante e urgente as crianças experivivenciarem ${ }^{9}$ o brincar livre no espaço escolar ou mesmo no espaço domiciliar no caso do ensino remoto? Acreditamos que no cotidiano pedagógico, tanto da educação infantil como do ensino fundamental, o brincar livre e espontâneo tem papel vital para as crianças, uma vez que é com a brincadeira que elas constroem seus conceitos acerca do mundo em que vivem, motivando-as a explorar, a experimentar e a re-criar. Ressaltamos que o brincar livre aqui é compreendido como uma potencialização da experiência lúdica que deixa fluir o espírito livre da criança, possibilitando-a agenciar produções que evocam o pensar, o sentir e o imaginar de cenas da trama da vida. Isto é, um encontro com a potência do desejo de ser e de existir em sua singularidade.

A desvalorização do movimento natural e espontâneo da criança em prol do conhecimento formalizado expulsa a ludicidade do espaço de liberdade e ignora o brincar como uma prática social genuína das crianças, a qual promove interações e aprendizagens amplas entre estas e destas com os adultos.

A complexidade do problema acerca do brincar livre nos primeiros anos do ensino fundamental ocorre por várias razões, mas, Cardoso (2018) destaca a aceleração de colocar as crianças mais cedo na escola. Numa reportagem da Nova Escola (2018), sobre o não benefício de se antecipar a entrada no Ensino Fundamental, o texto destaca: "existe a tendência de se reduzir essa etapa, a sociedade urbana já não possibilita uma experiência integral para as crianças pequenas (CALÇA, 2018, s/p) ${ }^{10}$ ”. O texto aponta ainda que, ao ingressar nessa etapa de ensino, a criança sente a diferença na mudança de ciclo, e os próprios alunos falam dessa quebra de expectativa tão cedo - “A professora não me chama mais pelo nome, não posso mais brincar" (Idem).

Com a inserção mais cedo da criança no ensino fundamental, a escola vem criando uma relação com o saber de forma uniformizada, por meios de aquisição e transmissão do conhecimento, para além de toda a diferença individual, de classe ou de pertença cultural. De maneira geral é o aluno - mais do que a criança - de quem a escola se ocupa (SARMENTO,2011). Essa problemática advém de estruturas que as instituições escolares têm cultivado em seus territórios, transformando-se em "máquinas de produção de subjetividade capitalista, desde a entrada da criança no mundo das línguas dominantes, com todos os modelos tanto imaginários quanto nos quais ela deve se inserir" (GUATTARI; ROLNIK,2013, p.49). O pesquisador Gandhy Piorski (2016) auxilia-nos na compreensão desta máquina capitalista e nos alerta:

\footnotetext{
${ }^{9}$ Experivivência é o termo utilizado por Conceição Lopes, que traz a junção das palavras: experiência e vivência. Para a autora, o brincar espontâneo é intrinsecamente automotivado. "As crianças brincando, entre si, comunicam consigo próprias e com os outros, compartilham e revelam o que pensam, como dizem os mundos das suas experivivências” (LOPES, 2016, p.9).

10 Revista Nova Escola Como está a discussão da idade mínima no Ensino Fundamental? Disponível em: $<\underline{\text { https://novaescola.org.br/conteudo/11810/como-esta-a-discussao-da-idade-minima-no-ensino-fundamental } \geq .}$
} 
Mesmo quando se colocam as crianças em suas prioridades de desenvolvimento econômico, perpetuação da espécie, modulação educacional, doutrinação política/religiosa, sanitarismos preventivos, ou como clientes de um amplo mercado de consumo, o resultado parecer reproduzir um permanente ciclo de distanciamento da criança (PIORSKI, 2016, p.37).

A esse pensamento, juntamos as reflexões de Walter Kohan (2019), no prefácio do livro “Infância e pós-estruturalismo", quando afirma que é preciso e possível problematizarmos as infâncias, os tempos e as relações com a escola. $\mathrm{Na}$ tese apresentada pelo autor, "o próprio da criança não é ser apenas uma etapa, uma fase quantificável da vida humana" (KOHAN,2004, s/p). A criança deve ser marcada com o movimento e a experimentação, o que temos chamado de criançar. A respeito disto, nos propõem a pensar:

O tempo presente, do estar presente, inteiramente, no que se faz, na vida que se vive: como uma criança que brinca. Trata-se de uma simples inversão: em vez de pensarmos em escolarizar cada mais a infância e a educação infantil, bem poderíamos infantilizar a escola e a educação fundamental. (KOHAN, 2019, p.13).

Reconhecemos que a escolarização das crianças é uma questão dilemática, pois se por um lado sabemos da importância da garantia de seu direito à educação como um direito humano e subjetivo, por outro, não podemos desprezar que muitas vezes as práticas escolares tendem a silenciar o corpo pulsante, vibrátil, curioso da criança em um processo progressivo de formação do adulto produtivo, "sério", ajustado. "Preparar" a criança para a vida adulta tem sido um dos grandes objetivos. Lembremos, mais uma vez, a pergunta: "o que você quer ser quando crescer?”. E, como a "vida adulta não é brincadeira", os currículos vão restringindo ano a ano as brincadeiras livres na escola. Os enunciados vão se atualizando e subjetivando as crianças, os adolescentes e os adultos. Quem já não ouviu a expressão "você está grandinho para esse tipo de coisas!"? Assim, a escola vai se tornando um espaço para os "grandes". Os currículos, por sua vez, como dispositivos que orientam o processo formativo vão se atualizando a fim de responder: o que ensinar, o que aprender e em que tempo?

\section{O currículo escolar de tradição ocidental: o que ensinar, o que aprender?}

Partimos do entendimento de que os desafios que se impõem à atividade educativa são efeitos de uma tradição ocidental que, para Gallo (2012, p.1), "tem sido pensada em matriz platônica, que afirma o aprender como recognição" e, portanto, da recordação daquilo que a alma racional já sabia, se mas esqueceu ao habitar um corpo material. Embora muito temos desviado desse essencialismo platônico, vimos que ele ainda permanece ora mais, ora menos, ora muito mais, ora muito menos, nas propostas curriculares. Entretanto, em que pese essa tradição ocidental, Gallo (idem) nos lembra que no século XX, com a Psicologia Educacional, a noção de ensino-aprendizagem, de modo indissolúvel, ganha ênfase nos processos educativos. Desde então, pensar na aprendizagem é, também, pensar no ensino. Aqui nos 
encontramos com um ponto problemático: haveria necessidade de ensinar uma criança para ela aprender a brincar?

Com Gallo, em seus atravessamentos com a filosofa da diferença, ao problematizar a questão, vai nos advertir que

[...] o processo educativo pode, então, ser tomado em uma perspectiva científica, dando segurança ao professor sobre como ensinar e como avaliar o aprendizado de cada aluno. A questão é que este controle sobre o aprendizado, através do ensino, leva a uma homogeneização: o objetivo é que todos aprendam as mesmas coisas, da mesma maneira (GALLO, 2012, p. 2).

$\mathrm{Na}$ tentativa de levar ensinar a todos e, na expectativa de que todos aprendam as mesmas coisas, de uma mesma maneira, não estaríamos caindo nas armadilhas de um conhecimento ideal, verdadeiro e "puro"?

Ao discorrer sobre o projeto filosófico da contemporaneidade, Deleuze (2000, p. 259) no apêndice da obra Lógica do Sentido, intitulado Platão e o Simulacro, assim provoca: "que significa 'reversão do platonismo’? Nietzsche assim define a tarefa de sua filosofia ou, mais geralmente, a tarefa da filosofia do futuro. Parece que a fórmula quer dizer: a abolição do mundo das essências e do mundo das aparências".

Para Souza e Tebet (2017, p. 111), “essa reversão passava por uma problematização da identidade em face à diferença” e, portanto, é preciso pensar a diferença não como um desvio em relação a um padrão a ser seguido, mas antes e primordialmente, como uma demolição da distinção entre modelo e cópia. Contudo, conforme aponta Gallo (2012), não nos afastamos muito dos modelos duais (platônicos, modelo-cópia), haja vista que as concepções pedagógicas da modernidade ainda estão alicerçadas em um binômio, em duas ações principais, quais sejam, ensinar-aprender.

Apoiando-se em Deleuze, Gallo nos provoca a pensar de que não podemos controlar o que alguém aprende. Para ele,

essa imprevisibilidade do aprender joga por terra toda a pretensão da pedagogia moderna em ser uma ciência, a possibilidade de planejar, controlar, medir os processos de aprendizagem. Aquilo que a pedagogia controla é aquilo que o professor pensa que ensina, seu currículo, seus conteúdos e suas técnicas; mas para além deste aprendizado quantificável e quantificado, há como que um "aprender quântico", um "aprender obscuro", como diz Deleuze, que em princípio nem o próprio aprendiz sabe que está aprendendo. Não há métodos para aprender, não há como planejar o aprendizado. Mas o aprender acontece, singularmente, com cada um. (GALLO, 2012, p. 4-5, grifos do autor)

É nesse sentido do aprender quântico, do aprender obscuro que insistimos na importância da brincadeira livre, quando as crianças podem (e devem) criar seus modos de existir, suas realidades, suas singularidades. Entendemos que as brincadeiras "dirigidas", "monitoradas", "supervisionadas" por um adulto que dita o "como brincar", reafirmam os modelos-cópias, capturando as potências do desejo na e 
da criança. Com isso, não estamos dizendo que tais atividades devam ser extintas dos currículos, pois, como dissemos na introdução desse texto, importa-nos o plano comum. O que queremos afirmar é o político do criançar, como conteúdo escolar que não pode ser colocado à margem do processo educativo escolar.

\section{O brincar livre e aprendizagem inventiva}

A liberdade é tema de grande interesse quando nos dedicamos a pensar no brinca livre da criança. Conforme Bergson (1988) a liberdade é uma ação, um ato imerso de interioridade. O ato livre parece ser aquela ação pela qual conseguimos nos exprimir em toda a abrangência de nossos sentimentos, de nossas vontades e de nossos pensamentos. Para o filósofo, “[...] somos livres quando nossos atos emanam de toda a nossa personalidade, quando a exprimem, quando com ela têm a indefinível semelhança que, por vezes, se encontra entre a obra e o artista” (BERGSON, 1988, p. 120).

Entendemos que o criançar só pode ser entendido enquanto duração, no sentido bersoniano. Em estudos anteriores, pudemos registrar esse criançar e capturar algumas das infinitas possibilidades que as brincadeiras livres podem provocar nas crianças. São devires intensos que nos remetem às multiplicidades para a ideia de criança e de seus modos de criançar. A seguir apresentamos alguns desses registros.

Figura 01 - Projeto Baú Brincante: criança brincando na chuva.

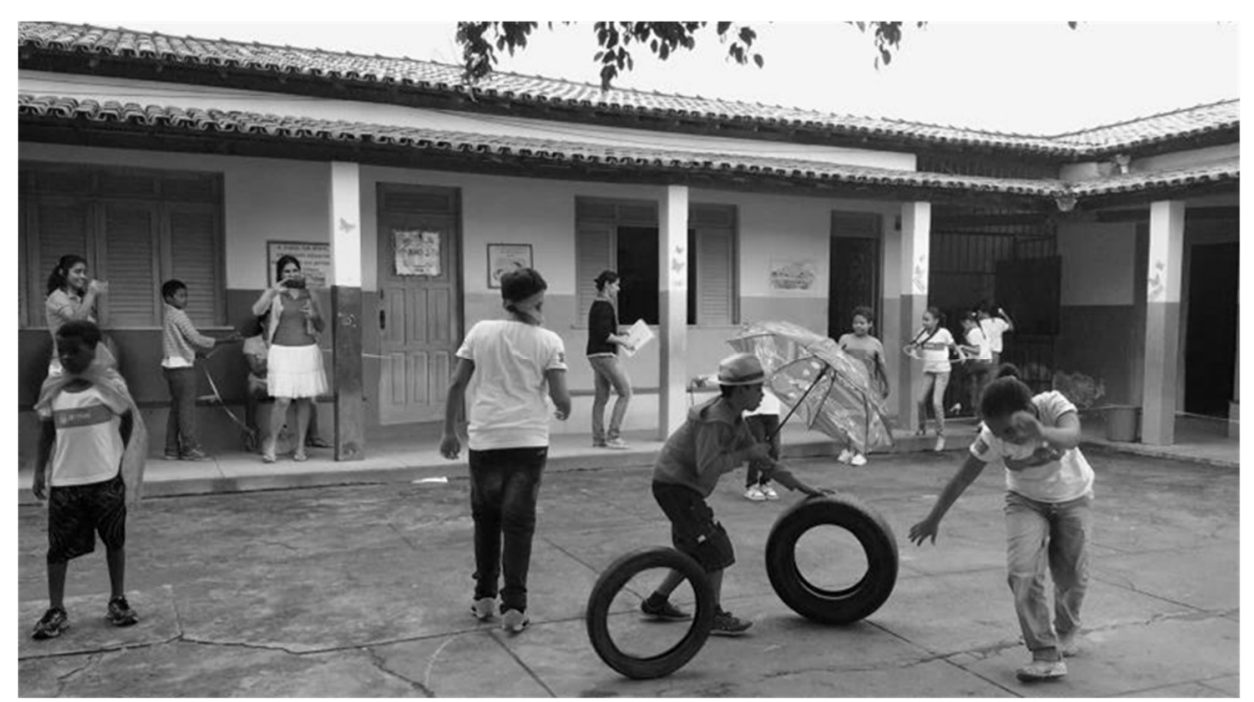

Fonte: Arquivos do Projeto Baú-brincante

Observar as crianças crianceando no pátio da escola provocou alguns sentimentos entre seus observadores. Luz, professora de algumas delas, assim se manifestou: 
[...] os super-heróis iam surgindo e o sonho de montar em um cavalo, mediante o brincar livre com a total liberdade de criação. O mundo da imaginação atrelado à criatividade. [...] é sentir um imenso praz̧er em estar presente realizando a arte. Nem a chuva foi impedimento para que não continuassem a brincar. (Luz- Dados do Diário - cedido por ela)

Um olhar para o brincar livre, em que as crianças são retiradas da mira da perspectiva de uma infância maior, nos leva a defender uma criança "afirmada em si mesmas, avessa a qualquer tutela; [...] seu próprio charme, seu modo de ser; [...] de produzir encontros e agenciamentos, um ir junto com as crianças" (GALLO, 2019, p.124-127). Assim, a vida é experimentada como ruptura, movimento, mudança. É o movimento do devir, de deixar fluir, de desconstruir e construir o outro em si. É diferençarse, no sentido deleuziano. (DELEUZE, 2006).

Olhar com seriedade a atividade da criança é, sobretudo, "falar um pouco de nós mesmos, quando nos colocamos diante da criança, como pais e ou educadores, estamos nos interrogando sobre o nosso próprio movimento a partir da criança que fomos.” (DIDONET, 2001, p.11). Talvez seja esse um bom momento de tensionarmos os modos como processos de subjetivação capitalísticos operam nos currículos escolares e vão criando as subjetividades adultas assujeitadas e ajustadas ao mundo do trabalho, afastados de suas potências. Recordamo-nos de uma expressão que nos alerta para as práticas discursivas nas escolas: "quem quer brincar vai para o parque de diversão. Escola não é lugar para brincar”. São, pois, com esses enunciados que lidamos e, contara a eles nos lançamos ao perspectivarmos as aberturas curriculares que tanto falamos.

Figura 02 - Crianças brincado na escola

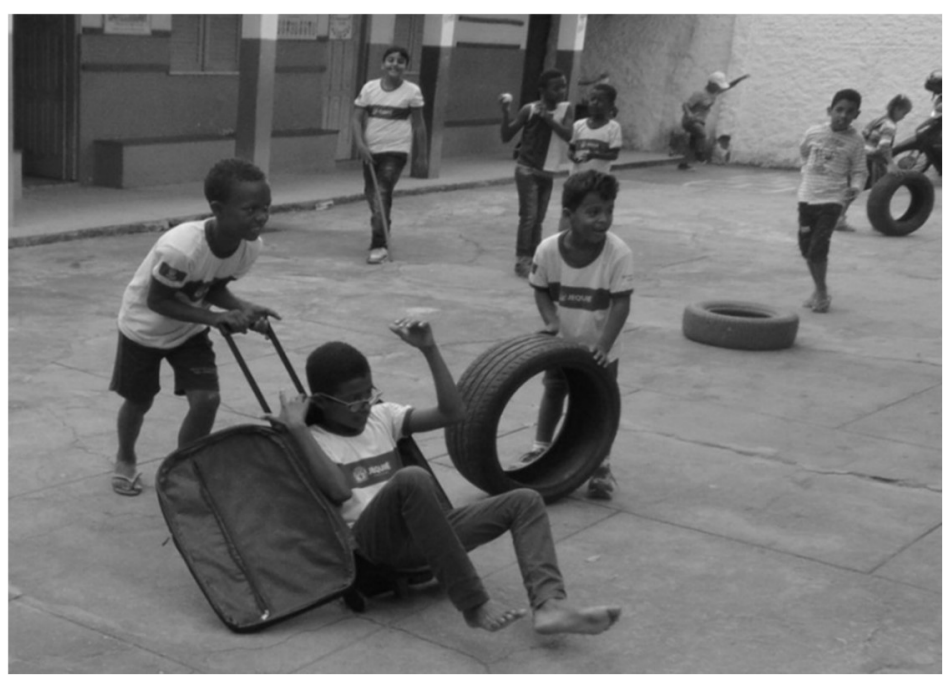

Fonte: Arquivos do Projeto Baú Brincante.

Os registros das crianças brincando no pátio da escola foram conteúdos das conversas produzidas nos ateliês, com a participação de professores, em torno do tema "um olhar sensível para a criança”. As professoras disseram sobre o que sentiam ao observar as crianças brincando. Luz, assim se colocou: 
uma criança. Ela vive como criança, ela não anda, ela corre. Ela é agitada, tem energia pura. Ela é alegria. Tudo remete a energia. Eu acho que a criança é verdadeiramente criança ali no Baú, brincando livremente. A criança sabe brincar. Eu acho que não se dá a possibilidade para a ela brincar (Luz, Ateliê/Olhar-16/08/17)

O cerne à vida das crianças na escola de ensino fundamental também é identificada em estudos de alguns autores, que sinalizam a existência da cristalização de um modo de ser criança no contexto escolar, por valorizarem mais a dimensão "aluno" do que em suas especificidades infantis e da cultura lúdica da criança. Conforme Sarmento (2011, p.588), “[...] de algum modo, perante a instituição, a criança "morre", enquanto sujeito concreto, com saberes e emoções, aspirações, sentimentos e vontades próprias, para dar lugar ao aprendiz”. Este modelo de ser aluno é incorporado pela própria condução dos educandos em suas relações com a organização escolar, com a cultura escolar, com os deveres e a relação formal com a aquisição dos conhecimentos.

Segundo Flor, na escola, a criança é "mais aluno", pelo tipo de sociedade que as pessoas vivem atualmente. Para ela, as crianças não se veem como crianças, ou, não querem ser vistas como crianças.

A criança não se vê como criança, parte, também, do modelo de sociedade que estamos vivendo boje. Elas, hoje, não querem ser vistas como criança. Infelizmente, acho que, essa emancipação da criança também não está ligada só pela questão da escola, mas de um modelo de sociedade que nós estamos vivendo. Ela não é vista pela sociedade como criança, não só pela questão do trabalho infantil; é a questão dessa propaganda que você vê na mídia. O conteúdo que se oferece na TV, na internet, hoje. Infeliżmente é uma reproducão imposta pela mídia. (Flor, Ateliê/Olhar - 16/08/17)

As falas da Professora Flor trazem elementos importantes para se pensar alguns pontos sobre a criança e seus processos de subjetivação. Primeiro quando a professora afirma que a criança não se vê como criança. Para Sayão (2002, p. 57), essa afirmação reflete a cultura adultocêntrica, que afirma:

[...] a cultura "adultocêntrica" leva-nos a uma espécie de esquecimento do tempo de infância. Esquecemos gradativamente como, enquanto crianças, construímos um sistema de comunicação com o meio social que, necessariamente, integra o movimento como expressão. Com este esquecimento, passamos, então, a cobrar das crianças uma postura de seriedade, imobilidade e linearidade, matando pouco a pouco aquilo que elas possuem de mais autêntico - sua espontaneidade, criatividade, ousadia, sensibilidade e capacidade de multiplicar linguagens que são expressas em seus gestos e movimentos. Os adultos tendem a exercer uma espécie de dominação constante sobre as crianças, desconhecendo-as como sujeito de direitos, até mesmo não reconhecendo o direito de movimentarem-se.

Há, nas brincadeiras livres, registros do cotidiano das crianças que nos convocam a pensar sobre elas, seus modos de agir, seus desejos, seus silêncios, suas produções de realidade. Com isso não queremos aproveitar as brincadeiras das crianças para, sobre elas, construirmos discursos de juízos. Importa-nos, respeitosamente, afetarmo-nos com os seus modos de criançar, como acontecimentos. São mundos produzidos (ou quem sabe reproduzidos), deixando-nos ver a esse mundo "estranho" das crianças, que um dia também nos foi familiar. Um espaço de criação pedagógica, por meio da exploração e de “constante movimento, de maneira que se é múltiplo em si mesmo" (NODARI; CORAZZA, 2019, p.8). Observar essas crianças é lançarmo-nos em nosso devir-criança, banhados de sentimentos e sensações 
provocantes. Com isso pensamos: poderia um currículo devir-criança? A seguir, temos um registro de uma criança em seu "mundo" e o diálogo com sua professora.

Figura 3 - A criança e seu "mundo"
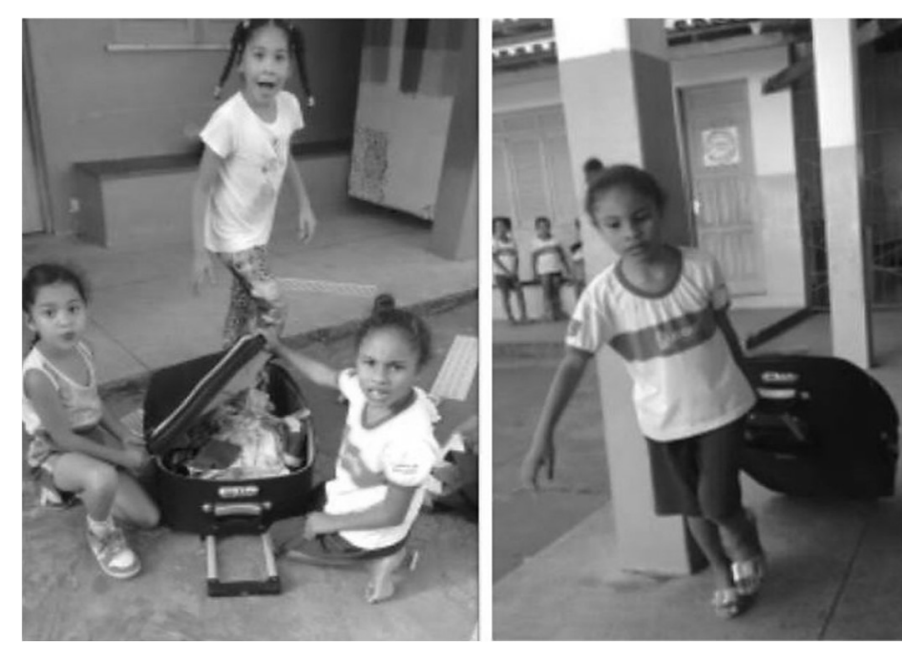

Fonte: Arquivos do projeto Baú Brincante

Sinto paixão - Eu registrei essa foto de Camila, porque en fiquei apaixonada. Ela estava com esse salto alto, puxando a mala, com maior prazer. E essa mala tinha era é coisa, viu! (risos). Quando eu vi, eu perguntei:

- Ob minha filha tá indo pra onde?

Ela responde: - Estou indo para outros estados.

Ela estava de salto alto, com a mala cheia. Ela não sabe se estado, cidade, país tem diferenca. Mas, volta e meia ela diz que vai para algum lugar. Ela já ouviu essa palavra, estado. Na outra semana, ela colocou o salto vermelho, arrumou a mala e falou que iria para Paratinga - Professoras sorriem e perguntaram, onde fica essa cidade Paratinga Luq? Ela sorri e responde: - É uma cidade do interior da Babia. (risos).

(Luz, Dados do Ateliê/Escuta-set/17)

Não temos dúvidas de que a escola pode criar formas e caminhos de oferecer para a criança a oportunidade de conhecer um mundo diferente daquele em que ela vive. Isso desperta a curiosidade e oferece a ela outras referências. As brincadeiras mexem com as fantasias e as imaginações infantis não estão distantes da vida real. Pelo contrário, elas estão altamente ligadas à cultura de uma sociedade, ao mesmo tempo reproduzindo-a e sendo produzidas por ela. Para Brougère (2006, p. 63), "o brinquedo pode ser considerado uma mídia, que transmite à criança certos conteúdos simbólicos, imagens e representações reproduzidas pela sociedade que a cerca". Assim, uma maneira da cultura interferir nos modos de brincar é através da produção dos brinquedos em sua forma material.

O brincar livre é a experimentação que enriquece o uso da linguagem, por oferecer à criança a oportunidade de expressar os próprios conceitos, ao atribuir outros sentidos a objetos que já trazem, em si e por si, significados dominantes. Acreditamos que a brincadeira livre possibilita acessar o lúdico. Ver crianças brincando nos causa a sensação de que ela "torna-se verdadeiramente uma criança”, como aponta a professora Luz. Para nós, o criançar. A professora Flor, já nos traz outro sentimento. Para ela, 
[...] Era perceptivel a genuina alegria, pura e simples e com um poder mágico de contagiar a todos em volta. [...] as crianças estavam em êxtase, uma energia que vibrava nos olhos de cada um, curiosos a experimentarem tudo ao redor. E naturalmente sem nenbuma interferência é possivel ver renascer brincadeiras que não fazparte do dia a dia dessa geração. (Flor Relato livre-janeiro/18)

Discutir o brincar livre no dentrofora escola dos anos iniciais do ensino fundamental tem sido um desafio no sentido de territorializar a brincadeira livre como conteúdo escolar que não se ensina, mas que se aprende. Como então seria possível aprender sem alguém que ensine, que conduza o aprendizado? Existe aprendizagem nestes termos?

Para nos ajudar a pensar sobre essas questões, Kastrup (2005) propõe o conceito de "aprendizagem inventiva", a partir do qual duas considerações importantes devem ser destacadas: a) a distinção entre criatividade e invenção, sendo a primeira a capacidade de produzir soluções diante dos problemas e a segunda como exatamente o inverso, ou seja, a invenção de problemas ${ }^{11}$; b) quais as implicações de pensar a aprendizagem a partir do conceito de invenção? De acordo com a autora, enquanto a psicologia tradicional ateve-se às noções de inteligência e mecanicidade para tratar da aprendizagem, notadamente, através das concepções behavioristas e gestaltistas, os estudos de Deleuze e Guattari acerca da produção da subjetividade tornaram possível o que ela chama de "aprendizagem inventiva", que "inclui então a invenção de problemas e revela-se também como invenção de mundo. Trata-se de dotar a aprendizagem da potência de invenção e de novidade” (KASTRUP, 2005, p. 1277).

Sílvio Gallo (2012) propõe uma análise da aprendizagem a partir de duas obras do filósofo francês Gilles Deleuze, Proust e os Signos (1964) e Diferença e Repetição (1969). Apesar de Deleuze nunca ter escrito especificamente sobre a Educação, Gallo enfatiza que nestes escritos é possível encontrar uma “"quaseteoria do aprender' numa direção distinta daquela da tradição ocidental, centrada na recognição platônica" (2012, p. 2). De acordo com o autor, o deslocamento proposto por Deleuze no que se refere à emissão dos signos apresenta uma diferenciação consubstancial em relação às concepções tradicionais por colocálos como condição necessária à aprendizagem e não ao ensino, portanto, aprender seria um encontro com os signos. São relações de signos que se estabelecem e movem o indivíduo em direção ao aprendizado. O professor, um mediador ou quem quer que seja não controla este aprendizado, posto que ele só se efetiva quando o aluno entra nesse regime de signos e nele se estabelece.

Ou seja, numa mesma aula, com um mesmo professor, múltiplas aprendizagens acontecem, na medida em que são múltiplos os alunos e que cada um aprende a seu próprio modo. A heterogeneidade de que fala Deleuze é esta multiplicidade. É por esta razão, por ser relação, que o signo implica em heterogeneidade, em diferença, e não em mesmidade, na contramão dos esforços de toda a pedagogia escolar com sua maquinaria de serialização, de produção de subjetividades em série (GALLO, 2012, p. 8).

Ora, se a brincadeira livre atinge esse status de conteúdo escolar, ela passa a fazer parte da sala de aula, do dia-a-dia da criança. A sala de aula rompe suas fronteiras físicas, vai ao pátio, chega ao domicílio.

\footnotetext{
${ }^{11}$ Kastrup toma emprestado as definições de criatividade dos estudos de Joy Paul Guilford e a de invenção da filosofia de Gilles Deleuze.
} 
Com isso, entendemos que mesmo em tempos pandemia, quando a escola se desloca para os domicílios das crianças, é importante que seja preservado o seu “tempo escolar de brincar". Estamos, pois, seguindo em direção a perspectivar um currículo menor. Uma educação como solidariedade, agenciamento coletivo de desejo entre adultos e crianças, pensada, perspectivada e implicada, como nos sugere Gallo (2019, p.129), “'co-íre' - caminhar juntos, produzir juntos, aprender juntos, criar juntos...conviver, partilhar a vida e nesta partilha produzir um futuro comum."

\section{Perspectivando um currículo menor...}

Pensando no deslocamento conceitual que Sílvio Gallo (2002) propõe em relação à obra de Deleuze e Guattari, Kafka: por uma literatura menor (2017), a educação praticada no Brasil poderia ser chamada de uma "educação maior”, ou seja, "aquela dos planos decenais e das políticas públicas, dos parâmetros e das diretrizes, aquela da constituição e da LDB, pensada e produzida pelas cabeças bempensantes a serviço do poder [...] é aquela instituída e que quer instituir-se, fazer-se presente, fazer-se acontecer" (GALLO, 2002, p. 173).

$\mathrm{Na}$ obra acerca da produção literária de Kafka, os filósofos franceses consagram o termo literatura menor, já presente na obra do próprio autor. Kafka: por uma literatura menor dá aderência à expressão nos meios acadêmicos e ganha caráter de natureza subversiva, carregada de devir (ROSA, 2016). Neste sentido, a literatura dita como menor não é aquela que se faz em uma língua menor, mas antes e primordialmente aquela que subverte uma língua maior em favor de uma minoria.

As três características da literatura menor são a desterritorialização da língua, a ligação do indivíduo no imediato político, o agenciamento coletivo de enunciação. É o mesmo que dizer que 'menor' não qualifica mais certas literaturas, mas as condições revolucionárias de toda literatura no seio daquela que se chama grande (ou estabelecida) (DELEUZE; GUATTARI, 2017, p. 39)

Ao transpormos tais características para a educação, podemos pensar que uma educação menor enquanto ramificação política, como ato político, se configura como um agenciamento maquínico na força desejante do professor militante e agenciamento coletivo de enunciação na relação entre estudantes e um contexto social e, portanto, situada no campo micropolítico. Propomos, então, pensar a educação e o papel do professor para além da crise educacional que vivemos atualmente, seja pela defasagem salarial, pela situação caótica de infraestrutura das escolas, do transporte e de tantas outras questões proeminentes quando se fala em educação no Brasil. Para tanto, devemos pensar em super professores? Não! Para o professor e filósofo Luiz Orlandi (2015, 26 min 24 s),

[...] por mais impotente ou frágil que seja a nossa inserção na máquina, existe sempre a possibilidade que a própria realidade acaba criando, para se fazer o mínimo; criar um pequeno acontecimento - estudando ou levando alguém a sair do seu estado precário que o aluno participe não da aula propriamente dita, mas da agitação fecunda do professor, do movimento no qual está inserido. [...] Se fizermos o melhor que podemos 
fazer, estamos fazendo aquilo que é necessário e isso produzirá efeitos. Não podemos nos deixar levar pela impotência.

Criar este acontecimento, proposto por Orlandi, no âmbito da educação menor, seria pensar um currículo menor - que rompe com a tradição disciplinar da aquisição do conhecimento, como restauração de uma totalidade que foi fragmentada em diversas áreas do saber, num movimento de divisão da unidade em partes para colocá-lo na esfera da aprendizagem inventiva, ou seja, do pensamento como multiplicidade.

Gallo (2002, p. 175) apresenta como alternativa a tal questão a ideia de educação menor que se faz de forma "rizomática, segmentada, fragmentária, não está preocupada com a instauração de nenhuma falsa totalidade", uma vez que o apelo à identidade, fortemente presente na produção do pensamento ocidental, afastou o valor coletivo da produção de singularidades, posto que esteve pautado na tentativa de resgatar uma totalidade perdida, do conhecimento como modelo arbóreo.

Para tanto, na educação menor caberia repensar não apenas a prática docente, militante e de resistência, mas a própria construção e aplicação de um currículo. Segundo Corazza, em O que quer um currículo (2001), ele, o currículo, está imerso em quatro dimensões: a) da linguagem, posto que significa não apenas aquilo que será captado do mundo e transmitido, mas também o fábrica na medida em que media a relação entre as coisas e nós, que o vivenciamos/fabricamos. É, portanto, um currículo falante; b) do "nós", a relação que o currículo falante estabelece como a nossa própria temporalidade e espaço; c) da vontade, um currículo dotado de linguagem, de temporalidade, atravessado por complexas relações socioeconômicas, histórico-culturais, deseja um sujeito; e d) da verdade, um currículo não pode produzir tudo, tão pouco de tudo saber, portanto, o sujeito que se relaciona com este currículo não produz uma verdade totalitária, mas pelo contrário, abre possibilidades para as diferenças e multiplicidades, pensando uma educação que vise potencializar saberes, trazendo à baila a riqueza, e o valor linguístico, cultural e plural dos sujeitos.

O currículo como composição, como um território formativo, se coloca como movimento, de uma realidade que se afirma na multiplicidade e na diferença. Isto posto, Gallo (2007, p. 07) nos lembra:

Com a imagem da árvore, ficamos na compartimentalização: os galhos vão se ramificando e se especializando cada vez mais, perdendo contato, pois cada ramo se autonomiza em relação aos demais, embora permaneçam todos parte da mesma árvore. Mas a comunicação entre os ramos de uma árvore fica dificultada, assim como fica dificultada e, quem sabe, impossibilitada, a comunicação entre as disciplinas num currículo escolar. [...] O currículo disciplinar, imageticamente representado na e pela árvore, faz de nós seres fragmentados, mas fragmentos que remetem a uma unidade perdida.

Se pensar o currículo a partir da imagem de árvore não dá conta das multiplicidades da realidade, com o rizoma - um emaranhado, mistura, produção de singularidades sem implicar em apelo à identidade, mas em valor coletivo na produção de singularidades - as construções são diferentes. 
Conforme evidenciamos anteriormente, a educação menor como rizomática é pensada também pelo viés de um currículo rizomático e menor. Embora o termo rizoma seja específico da botânica, ele é introduzido no campo da filosofia da diferença por Deleuze e Guattari na obra Mil Platôs (2019), com o sentido de uma proliferação, daquilo que realiza múltiplas conexões, sem centro ou hierarquia e que, portanto, estabelece infinitas maneiras de conexões, encontros e dimensões. Também realizando um deslocamento para o campo da educação, um currículo menor é aquele que traz em si a ideia de transversalidade, de uma produção de saberes que se atravessam e produzem tais conexões e encontros, nos quais não há que se esperar pela previsibilidade, posto que não há como prever como e o que será aprendido. Aqui o saber pode ser construído de forma livre, não hierárquica, tal qual o brincar das crianças.

Se a educação menor é aquela que atravessa e perdura a resistência, não para fins de tornar-se maior ou de produzir verdades e modelos, ela pensa a diferença ao invés do universal, pensa na liberdade, em que singularidade possa ser construída nos espaços educacionais. A construção de um lócus educacional desterritorializado, a partir dos desafios históricos já engendrados neste campo do saber, pode ser ensejado por meio deste currículo menor que não nos engessa ou paralisa, mas que nos carrega em potência ao imergirmos nas aventuras do desconhecido.

\section{Considerações Finais}

Iniciamos esse trabalho com o desejo de problematizar e tensionar a importância de agenciarmos vetores de forças no sentido de territorializar a brincadeira livre como um conteúdo escolar de grande importância para a formação das crianças. Para tanto, nos afastamos das narrativas que significam ou idealizam um modo de ser criança e nesse sentido preferimos investir na ideia do criançar, como um verbo, atravessado por toda a intensidade de seu movimento. Acreditamos que as crianças vão tendo os seus criançares silenciados na medida em que a escolarização avança, num processo de subjetivação modelar que as torna matérias-primas para o sucesso das sociedades capitalistas que carecem de subjetividades assujeitadas e ajustadas ao capital mundial integrado.

Seguimos noutra direção. Defendemos a necessidade de afirmarmos o desejo da criança, a fim de aproximá-la o quanto possa de sua potência de agir, em processos profundos de singularização. Tal movimento requer aprendizagens inventivas, cheias de criançares, não subsumidas ao processo de ensino. Não acreditamos que se ensina uma criança a brincar; ela, a criança, aprende a brincar em seus fluxos intensos de criançar. É, então, desse lugar, que vamos ao encontro do currículo "menor", aquele que retira a criança de um pedagogização cognitivista e se mostra como dispositivo molecular, tramado, complexo, capazes de fomentar processos de singularização da criança. 


\section{REFERÊNCIAS}

ABRAMOWICZ, A. Educação Infantil: implementar o exercício da infância. In: ; TEBET, G. G. C.(orgs) Infância \& Pós-estruturalismo. 2 ed. São Carlos: Pedro\& João Editores, 2019.

BERGSON, H. Ensaio sobre os dados imediatos da consciência. Tradução de João S. Gama. Lisboa: Edições $70,1988$.

BROUGÈRE, G. Brinquedo e cultura. 6. ed. São Paulo: Cortez, 2006.

CALÇA, P. Como está a discussão da idade mínima no Ensino Fundamental? Revista Nova Escola, em 30 de Maio de 2018. Disponível em: <https://novaescola.org.br/conteudo/11810/como-esta-a-discussaoda-idade-minima-no-ensino-fundamental $\geq$. Acesso em set. 2018.

CARDOSO, M. C. Catadoras do brincar: o olhar sensível das professoras acerca do brincar livre no ensino fundamental I e suas ressonâncias para a profissionalidade docente. Tese (doutorado) - Universidade Federal da Bahia. Faculdade de Educação, Salvador, 2018a. pp. 212.

CORAZZA, S. O que quer um currículo? Pesquisa Pós-Críticas em Educação. Petrópolis, RJ: Vozes, 2001.

D’ÁVILA, C. M.; CARDOSO, M.C.; XAVIER, A.A.S. O brincar livre na escola de ensino fundamental e formação de professores: a experiência do Baú Brincante. In: D’ÁVILA, C.; FORTUNA, T. R. (Orgs.). Ludicidade, Cultura Lúdica e Formação de Professores. Editora CRV, Curitiba, 2018, p.63-85.

DELEUZE, G. Platão e o simulacro. In: Lógica do Sentido. 4 ed. São Paulo: Perspectiva, 2000, p. 259-271.

DELEUZE, G. Diferença e Repetição. Tradução de Luis B. L. Orlandi e Roberto Machado. 2 ed. Rio de Janeiro: Graal, 2006.

DELEUZE, G.; GUATTARI, F. Kafka: por uma literatura menor. Tradução: Cíntia Vieira da Silva. 1 ed., 3 reimp. Belo Horizonte: Autêntica, 2017.

DELEUZE, G.; GUATTARI, F. Mil platôs: capitalismo e esquizofrenia, 2, v. 1. São Paulo: Editora 34, 2019 ( $3^{\mathrm{a}}$ reimpressão).

DIDONET, V. Creche: a que veio... para onde vai. In: Revista Em Aberto, Brasília, v. 18, n.73, p. 11-161. Jul.2001.

GALEANO, E. De pernas pro Ar: a escola do mundo ao avesso. Porto Alegre, RS: L\&PM, 2011.

GALLO, S. Em torno de uma educação menor. Revista Educação \& Realidade. Porto Alegre, v. 2, n. 2, p.169178, jul./dez. 2002. Disponível em https://seer.ufrgs.br/educacaoerealidade/article/view/25926. Acesso em 29 set. 2020.

GALLO, S. Currículo (entre) imagens e saberes. Palestra proferida no V Congresso Internacional de Educação. São Leopoldo. Pedagogias (entre) lugares e saberes, 2007. 
GALLO, S. Educação: entre a subjetividade e a singularidade. Revista do Centro de Educação, Santa Maria, v. 35, n. 2, mai./ago. 2010, p. 229-243. Disponível em https://periodicos.ufsm.br/reveducacao/article/view/2073. Acesso em 30 dez. 2020.

GALLO, S. As múltiplas dimensões do aprender. In: Anais do Congresso de Educação Básica: aprendizagem e currículo. Florianópolis, 2012. Disponível em: http://www.pmf.sc.gov.br/arquivos/arquivos/pdf/13_02_2012_10.54.50.a0ac3b8a140676ef8ae0dbf32 e662762.pdf. Acesso em: 27 out. 2020.

GALLO, S. Educação Infantil: do dispositivo pedagógico ao “ir junto" com as crianças. In: ABRAMOWICZ, A.; TEBET, G. G. C.(orgs.) Infância \& Pós-estruturalismo, 2 ed. São Carlos: Pedro \& João Editores, 2019, p.113-130.

GUATTARI, F.; ROLNIK, S. Micropolitica: cartografias do desejo. Petrópolis, RJ: Editora Vozes, 2010.

GUEDES, L. F. B. Arqueologia do olhar e os sentidos da carto(foto)grafia na formação em saúde mental. Revista Fórum Identidades. Itabaiana-SE, Universidade Federal de Sergipe, v. 28, p. 95-109, set./dez. 2018.

KASTRUP, V.; PASSOS, E. Políticas cognitivas na formação do professor e o problema do devir-mestre. Revista Educação \& Sociedade, Campinas, vol. 26, n. 93, p. 1273-1288, set./dez. 2005.

KASTRUP, V.; PASSOS, E. Cartografar é traçar um plano comum. In: PASSOS, E.; KASTRUP, V.; TEDESCO, S. Pistas do método da cartografia: a experiência da pesquisa e o plano comum. Vol. 2. Porto Alegre: Sulina, 2016.

KOHAN, W. O. Apontamentos filosóficos para uma (nova) política e uma (também nova) educação da infância. Rio de Janeiro, 2004. Disponível em: file:///C:/Users/Windows/Downloads/te walter kohan\%2020DEVIR\%20INFANCIA.pdf Acesso em 15 de março de 2021.

LOPES, M. C. Brincar Social Espontâneo na Educação de Infância: um estudo. Book (PDF). Dez. 2016. Disponível em:< https://www.researchgate.net/publication/313853101>.Acesso em: 3 de março de 2017.

ORLANDI, L. B. L. In: Deleuze e a Educação. Atta Mídia e Educação. Roteiro: Sílvio Gallo e Renata Aspis, 2015.21 vídeo $146 \quad \mathrm{~min}) . \quad$ Disponível https: / /www.youtube.com/watch?v=9v6HrC17rVo\&feature=emb_. Acesso em 24 de outubro de 2020.

NODARI, K. E. R.; CORAZZA, S. M. Procedimentos didáticos de invenção: a potência dos signos das artes. Educação em Perspectiva, Viçosa, MG, v. 10, p. 1-13. e-019016, 2019. ISSN 2178-8359.

PEREIRA, SOCORRO CABRAL, et al. Extensão Universitária em Tempo de Convid 19: experiências formacionais docentes em ambientes virtuais acerca do brincar e cultura lúdica no espaço escolar. In: COLACIQUE, R.; SANTOS, R.; AMARAL, M. (orgs). Práticas Pedagógicas em Tempos de Pandemia. 2021 (Prelo).

PIORSKI, G. Brinquedos do Chão: a natureza, o imaginário e o brincar. São Paulo: Editora Peirópolis, 2016.

ROSA, F. M. S. C. A literatura menor em Deleuze e Guattari: por uma educação menor. Revista educação, Santa Maria, v. 41, n. 3, p. 685-696, set./dez. 2016.

SARMENTO, M. J. A reinvenção do ofício de criança e de aluno. Atos de Pesquisa em Educação PPGE/ME FURB - ISSN 1809-0354 v. 6, n. 3, p. 581-602, set./dez. 2011. 
SAYÃO, D. Corpo e movimento: notas para problematizar algumas questões relacionadas à educação infantil e à educação física. Revista Brasileira de Ciências do Esporte, Campinas, v. 3, n. 2, p. 55-57, jan. 2002.

SOUZA, R. M.; TEBET, G. G. C. Diversidade, diferença e mal-estar: ensaio para novos modos de pensar o ato educativo. Políticas Educativas. Santa Maria, v. 11, n. 1, p. 107- 122, 2017.

SPINOZA, B. Ética. Tradução de Tomaz Tadeu. 2 ed., 10. Reimpressão. Belo Horizonte: Autêntica, 2020. 